\title{
A Softcomputing Knowledge Areas Model
}

\author{
Labib Arafeh* and Bashar Mufid
}

Najjad Zeenni Faculty of Engineering, Al-Quds University, P.O. Box 20002, Jerusalem, Palestine

\begin{abstract}
Recently, ten knowledge areas (KAs) of project management have been published by the PMBOK@ Guide. They comprise specific skills and experiences to ensure accomplishing project goals, and include management of: integration, scope, cost, time, quality, communications, procurement, risk, human resources and stakeholders. This research paper focuses on the ten required KAs for a project manager or a project to be successful. It aims at applying the Softcomputing modeling techniques to describe the relations between the 47 processes and the KAs. Such a model will enable users to predict the overall competencies of the project management. Thus, it provides an assessment tool to envisage, visualize and indicate the overall performance and competency of a project.
\end{abstract}

The proposed Softcomputing Knowledge Areas Model (SKAM) is a two-stage model. The first stage involves ten models. Each model describes relations between a specific KA and its related processes. The outputs of these ten models will feed into the second stage that will represent the relationship between all the ten KAs and the overall predicted competencies of a project. A combination of Subtractive Clustering and Neurofuzzy modeling techniques are used. Three measures are used to validate the adequacy of the models: the mean average percentage errors, the correlation coefficient and the maximum percentage errors. The highest achieved values for these measures are $0.5751,0.9999$ and 4.7283 , respectively.

However, although the preliminary findings of the proposed SKAM model are promising, more testing is still required before declaring the adequacy of applying the Softcomputing modeling approach in the project management field.

Keywords: Knowledge Areas, Project Management, PMBOK® Guide, Softcomputing, Modeling.

\section{INTRODUCTION}

A project is a temporary endeavor undertaken to create a unique product, service or result, by sharing human and non-human resources. Every project has its own characteristics in terms of: impermanency as each project has its own start, end and project team; uniqueness in terms of product, service or result; completeness in terms of objectives, acceptance and satisfaction; variables and parameters like nature, size, budget, resources and complexity; and categories, whether it is a small, a medium or a large project.

A project can also be viewed either as a set of required Knowledge Areas (KAs), competencies and skills to execute it, or as a series of processes. A process is a set of interrelated actions and activities accomplished to achieve a specified set of products, results, or services. Processes can overlap and interact throughout a project. They are usually described in terms of inputs (documents, plans, designs, etc.); tools and techniques; and outputs (documents, products, etc.). While some processes are executed in order; some are recurring ones that are executed at various stages throughout the entire project.

Management on the other hand, is a process concerned with accomplishing of objectives. It includes

*Address correspondence to this author at the Najjad Zeenni Faculty of Engineering, Al-Quds University, P.O. Box 20002, Jerusalem, Palestine; Tel/Fax: ++ 9702 2797023; E-mail: larafeh@eng.alquds.edu management groups like planning, organizing, directing and controlling. Project management involves the coordination of group activity wherein the manager plans, organizes staff, directs and controls resources to achieve an objective within constraints on time, cost, and performance of the end product.

Based on the above, project management can be defined as the application of knowledge, skills and techniques to execute projects effectively and competently in order to meet project requirements and client expectations. In other words, it is a process of implementing the management functions in the context of a project. The implementation process involves utilizing resources to meet the project's objectives. Project management is thus accomplished by appropriately applying and integrating the five process groups that comprise the 47 project management processes according to the $5^{\text {th }}$ edition of the PMBOK® Guide [1]. These 47 different processes are illustrated in Figure 1.

The essential processes that lead to the project's success are grouped in five process groups (initiating, planning, executing, monitoring and controlling, and closing) [1] to reflect the logical integration and interactions between the individual processes and the common purposes they serve.

The Association for Project Management (APM) has identified five dimensions of professionalism [2]: Breadth defined as the Body of Knowledge required to 


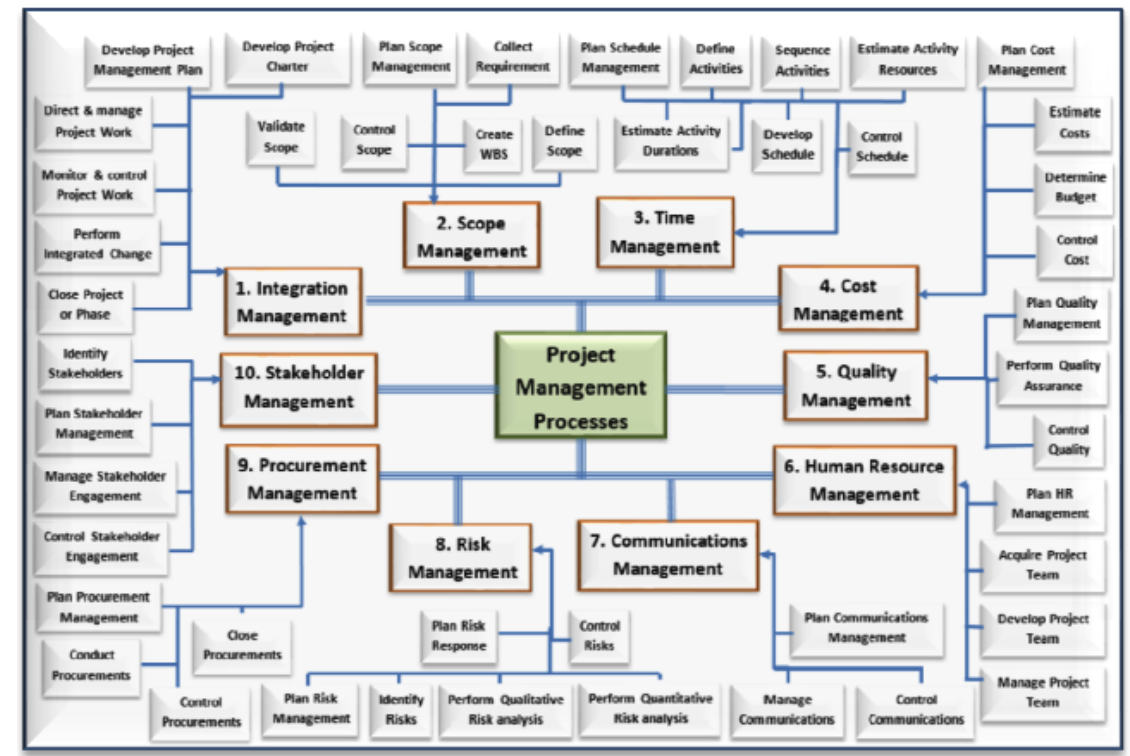

Figure 1: The 47 processes of a project Management Block Diagram.

manage a project; Depth defined as the Competence Framework which provides a guide to project management competencies; Achievement, encompassing all Qualifications, including the tools, techniques, processes and skills required to illustrate the project management achievement; Commitment, which aims at enhancing the ongoing professional development, and encouraging and recognizing individual lifelong learning opportunities in a rapidly changing environment; and Accountability, regulated by a Code of Professional Conduct, which outlines the ethical practice expected from any professional.

To measure an organization's project management maturity, the Project Management Maturity Model $\left(\mathrm{PMMM}^{\mathrm{SM}}\right)$ [3] has been used. Once the initial level of maturity and areas for improvement are identified, the PMMM provides a roadmap, and categorizes the required steps to take towards project management maturity advancement and performance improvement. To ensure an effective project management, a processbased method, which is known as Projects IN Controlled Environments, PRINCE2, is available [4]. PRINCE2 focuses on business justification, defines the organizational structure for the project management team, depends on product-based approach, divides the project into manageable and controllable stages, and can be implemented at any level appropriate to the project.

On the other hand, the Project Management Institute (PMI) has recently issued the latest $5^{\text {th }}$ edition of the PMBOK® Guide, which identifies ten KAs [5], comprising specific skills and experience in order to accomplish project goals. Each KA represents a complete set of concepts, terms, and activities that make up a professional project management field. In other words, every KA is made up of a set inputs, tools and techniques, and outputs. Moreover, each KA covers several process groups of a project, which, collectively, accomplish proven project management functions and drive project success. The ten KAs are formed by grouping the 47 processes of project management in to specific and concentrated areas. These KAs are [5] as tabulated in Table 1.

Since every KA involves different processes, the assessment of each process will provide an indication of the competency of that particular KA. This, in turn, will help judge and predict the overall competency and proficiency of the project.

These KAs will be the basis of the SKAM model developed in this paper, which is organized in five sections. After introducing the basics of project management and KAs in section 1 , section 2 surveys relevant studies which have addressed the problem of modeling KAs of project management. Section 3 briefly introduces the Softcomputing modeling techniques and presents the proposed SKAM model. While results and discussions are covered in section 4,conclusion and further work are presented in section 5 .

\section{RELEVANT STUDIES}

The project management field has been addressed by a lot of research studies. Recently, an intensive survey of the existing project management literature 
Table 1: Description of the Ten Knowledge Areas and their Related Processes

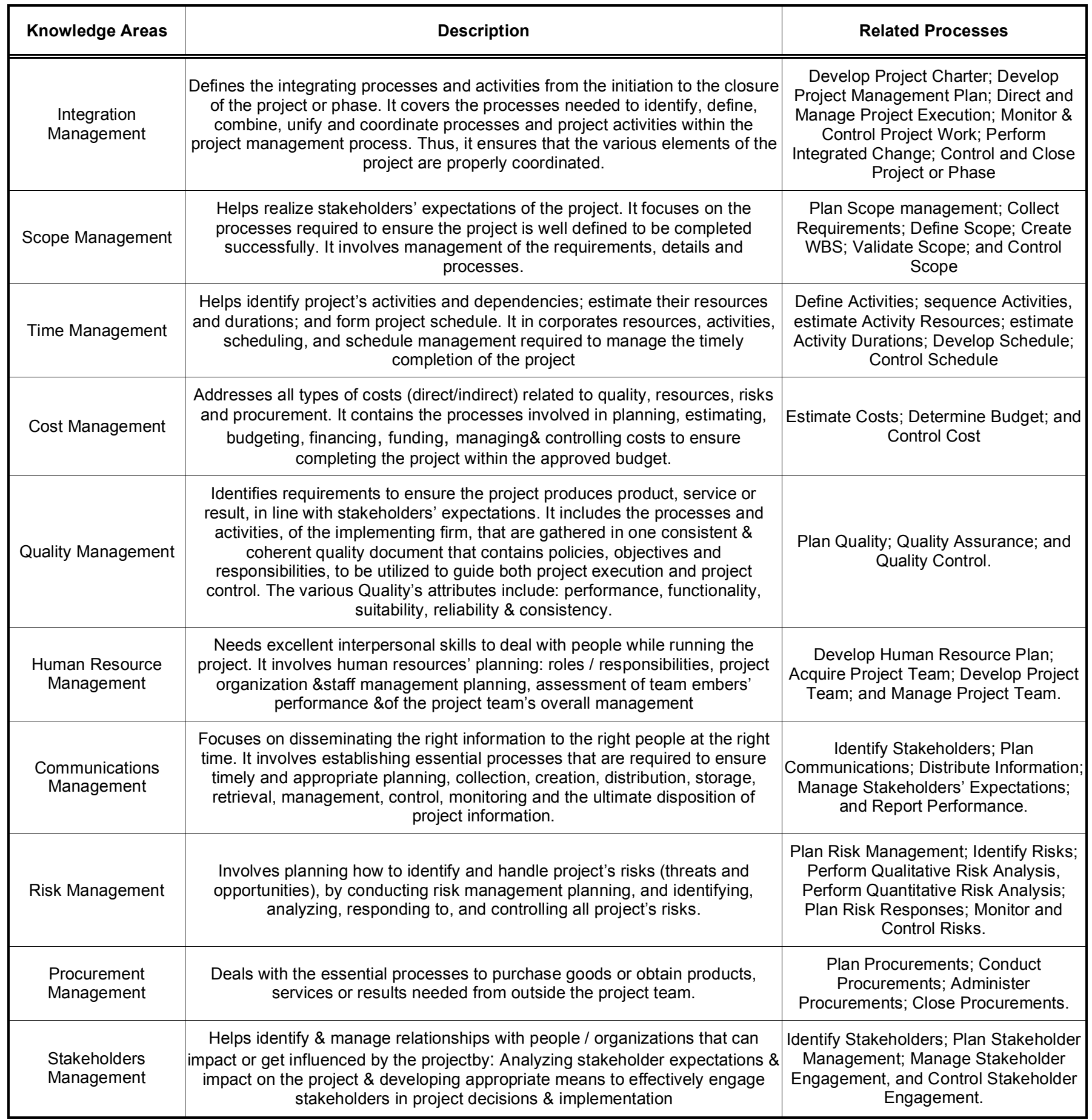

and research has been carried out by Singh and Lano [6]. The authors report four research works that address the implementation of the system modeling, estimation and object-oriented concepts for better project management. One paper suggests integrating the system dynamics approach to risks management within the existing project management processes. Another one proposes to implement system modeling as a communication tool for evaluating and gathering stakeholder expectations in an efficient way. Whereas a third paper applies the object-oriented approach to represent activities to share information through project management's phases, the fourth one introduces an estimation model based on actual and estimated data for prediction.

Based on the PMBOK Guide framework, Ramadan reports a comprehensive (1997-2011) survey of 130 
articles on project management published by the Project Management Journal [7]. The author focuses on the different KAs and reports the amount of articles that have addressed each KA. The percentage of addressed $\mathrm{KAs}$ ranges between $21.2 \%$ for time management and $1 \%$ for scope management.

To ensure higher software project success rates, the fuzzy logic approach is suggested by Siwani et al. to improve the estimation accuracy of all the tasks within the project management KAs [8]. The effectiveness of the Neural Networks and Fuzzy Systems is evaluated successfully by Goonawardene et al. in project management areas like job recruitment, prediction of project success/failures, and decision making process of employee performance appraisals related to any company/industry [9]. The research study states an achievement of a very high level of accuracy.

Several studies also address the Risk Management KA. These include: Hu et al.'s study which developed an intelligent risk evaluation model based on Neural Network and Support Vector Machine approaches[10]. The paper also developed an enhanced model, based on a combination of Neural Networks and the Genetic Algorithms that improved the performance of the other two approaches. Xiaoqing et al. introduced an experimental intelligent early warning system based on fuzzy logic to make sponsors, users and project managers aware of many potential risks as early as possible [11]. Fatih and Cengiz [12] presented an analytical tool to evaluate the project risks under incomplete and vague information making use of the fuzzy analytic hierarchy process. They reported a successful application of their system in evaluating the riskiness of an information technology IT project of a Turkish firm.

The Scope KA has been addressed by Hossein et al. [13]. The paper reviews various studies of applying Artificial Intelligence to Project management, and proposes an intelligent framework to control and manage the Scope $\mathrm{KA}$, and implement the proposed framework to generate the Work Breakdown Structure of two sample projects in the fields of building construction and electrical panel production.

Moreover, while Avots developed an Expert System to help project managers analyze and control project schedule [14], Nemati et al. proposed a hybrid intelligence system with expert system and artificial neural network components to aid in projectes timate validation and quality prediction of the deliverables [15].
Furthermore, a fuzzy decision making system is presented to measure the Project Management Efficiency [16]. They use measures such as project time delay and project time delay gradient. They also present a fuzzy logic-based project management efficiency and risk classification and measurement tool [17]. They focus on project's time, effort, human resources and required hardware and software. A project manager knowledge base is established to be competitive and to effectively execute sustainable projects applied in the field of green construction [18].

Eastham et al. presented a hierarchical decision modeling tool based on nine KAs of the project management body of knowledge [19]. It is a software selection for product lifecycle management. The tool makes use of five process gate offerings namely, researching, sorting, pairing down, evaluating and implementing. Rankings are allocated to the KAs and are assessed across the system offerings. The tool was validated by various case studies from different industries. A combination of an enterprise knowledge management system based on an environmentprocess-capability and a knowledge audit model was presented by Suo Bai-min et al. [20]. It was reported that such a tool enhanced the knowledge management capability of an enterprise.

Furthermore, based on an empirical study of 400 companies, Spalekassessed the Project Management Maturity level in areas like methods and tools, human resources, project environment and knowledge management areas [21].

It is worth mentioning that a project management online Assessment tool is available [22]. This tool contains 144 multiple-choice questions to measure the competencies of the ten PMBOK Guide KAs (integration, Scope, Time, Cost, Quality, HR, Communications, Risk, Procurement and stakeholders), Enterprise View, Business Acumen, Organizational Savvy and Productive Work Environment.

\section{THE PROPOSED MODEL}

A simple Softcomputing-based Knowledge Areas Model, SKAM, is proposed in this paper. SKAM can be used by organizations and project managers to judge or assess the ten PMBOK® Guide-based KAs' proficiency, competency and know-how [5]. SKAM is a two-stage model as shown in Figure 2.

In the first stage, every KA is modeled based on its related processes. Such a model will represent the 


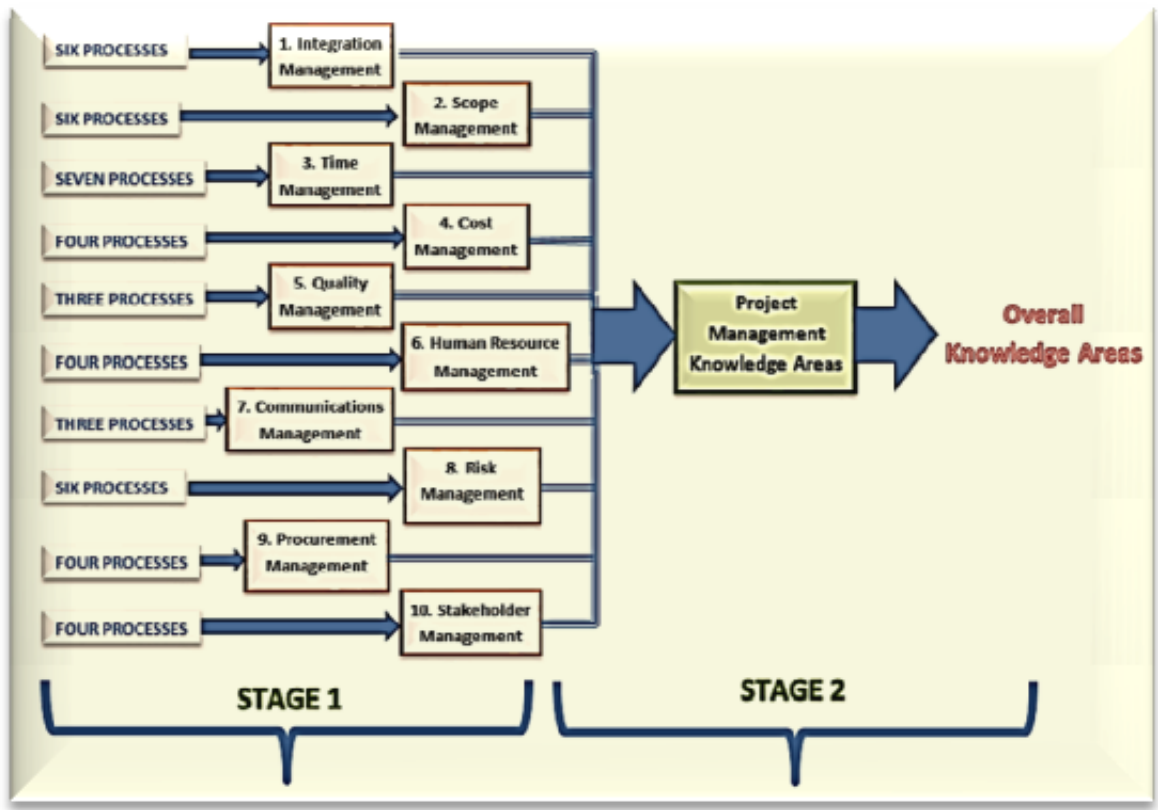

Figure 2: SKAM Model Block Diagram.

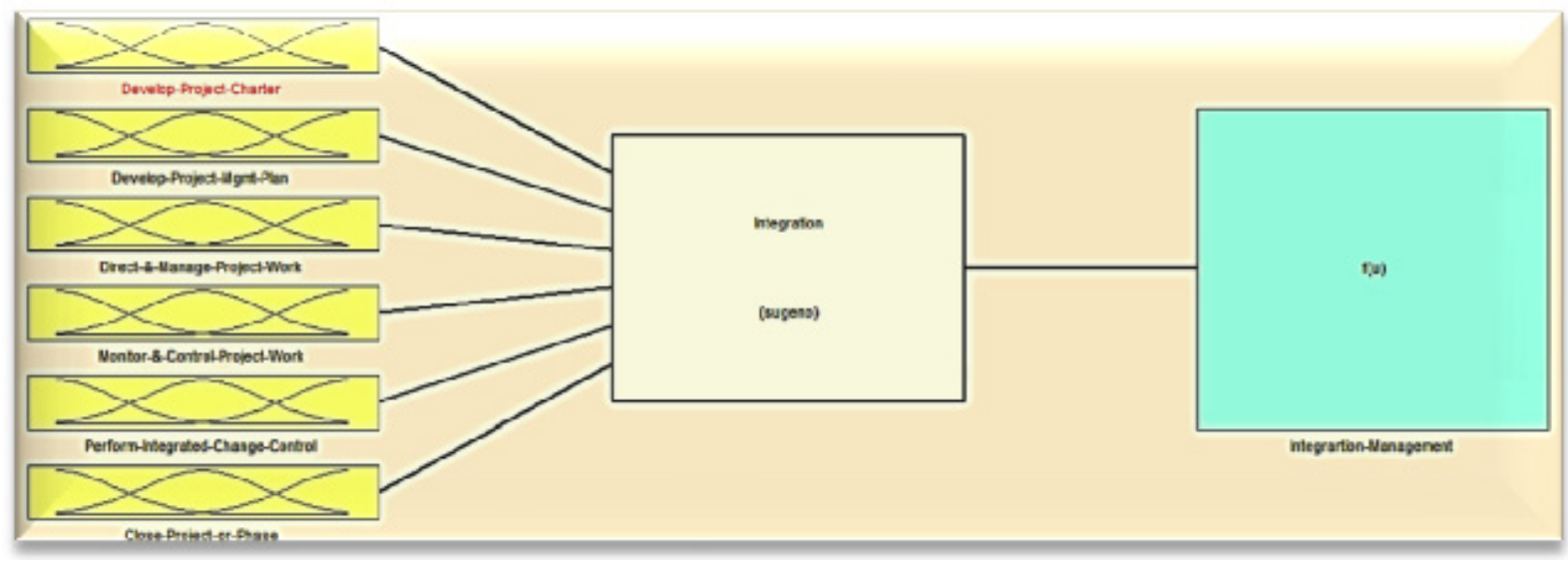

Figure 3: The Integration Knowledge Area and Its Associated Processes Block Diagram.

relations between the processes (as inputs) and their corresponding KAs (as an output). Since there are ten KAs, whose associated processes are depicted in Figure 1, there will be ten such models. Figure 3 illustrates an example of such models, the Integration $\mathrm{KA}$ model, whereby its six associated processes are the inputs of the model, which produces the Integration management as an output. This Integration model describes the relation between the six processes, with equal contributions of each process, and the predicted competency of the Integration management.

In the second stage, as illustrated in Figure 4, the ten KAs models are fed into the overall KAs model to produce the overall competency and proficiency of the project under consideration. Such a model describes relations between the competencies of the ten KAs, with equal contribution of each $\mathrm{KA}$, and the overall competency.

The following sub-sections briefly introduce the Softcomputing field and present a detailed description of the SKAM model.

\section{A. The Softcomputing Modeling Techniques}

Softcomputing is an emerging approach to computing, which mimics the remarkable ability of the human mind to reason and learn in an environment of uncertainty and imprecision [23].

Softcomputing is a combination of multidisciplinary approaches to model and enable solutions to real world problems. It encompasses several computing fields including fuzzy systems through the fuzzy if-then rules; 


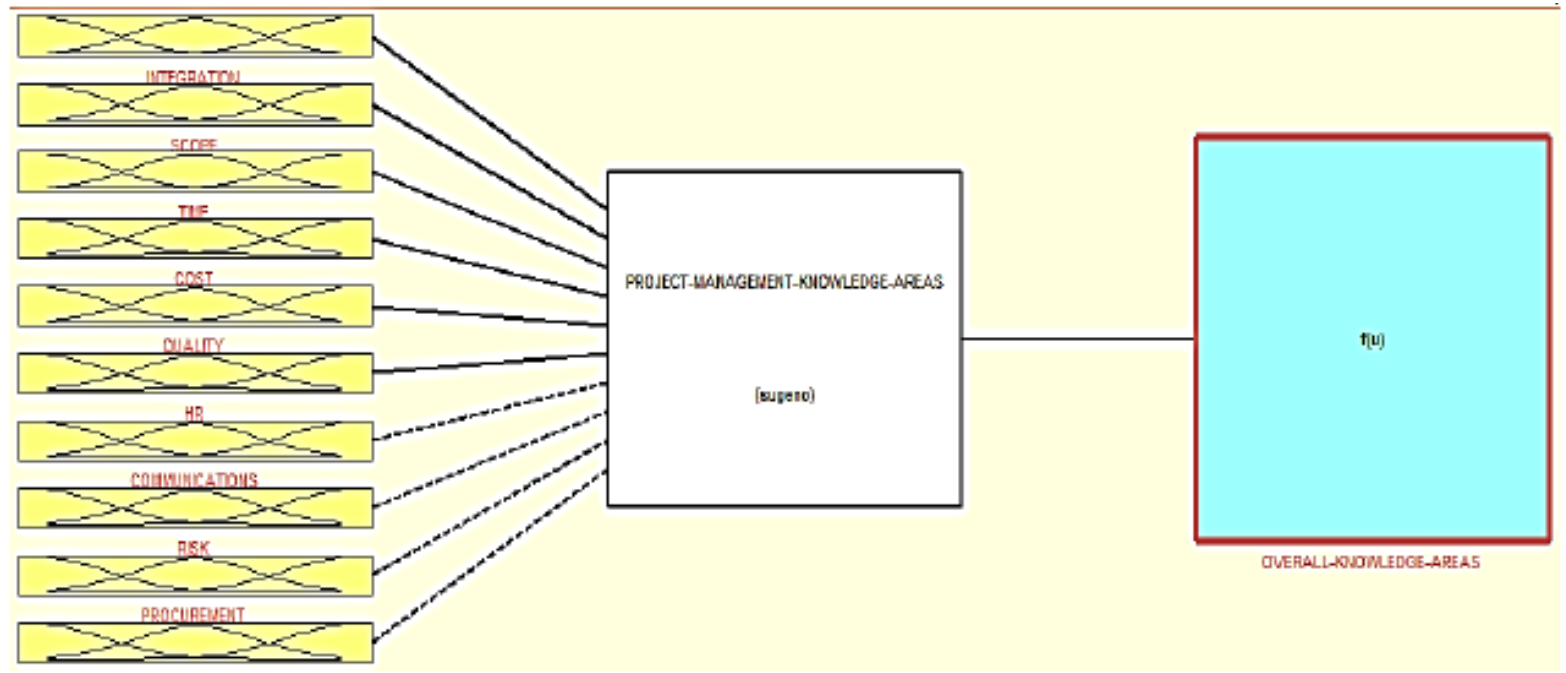

Figure 4: SKAM Project Management Ten Knowledge Areas Model.

Neural Networks for learning and adaptation; and Genetic Algorithms for evolutionary computation. Hybridization of these approaches will contain the various combined features such as the Neurofuzzy approach, which combines the Neural Networks and the Fuzzy Systems. Neurofuzzy will thus have the reasoning capability of the fuzzy systems and the learning and adaptation abilities from the Neural Networks.

The fuzzy Logic (FL) methodology incorporates human knowledge and performs inferences and decision-making depending on multi-value notions to solve problems instead of using Boolean logic. FL's basics are derived from fuzzy set theory [24, 25]. A fuzzy system (FS) is a mapping of an input data vector into a scalar output based on fuzzy logic, using the fuzzyfication, fuzzy inference, and defuzzification components. The fuzzyfication component maps a crisp input space into appropriate linguistic labels of fuzzy sets known as Membership Functions (MFs). The fuzzy inference component contains a rule base that holds fuzzy rules: a database that defines the MFs used in the fuzzy rules, normalizes the input and output universes of discourse, and performs the fuzzy partitioning of the input and the output spaces; and a reasoning mechanism that performs the inference process upon the rules and given condition to derive a reasonable output. The defuzzification component converts the aggregated fuzzy set to a crisp output value. The Neural Networks (NNs), is an information processing paradigm stimulated by biological nervous systems such as our brain. NN is composed of large number of highly interconnected neurons working together. NN learns from experience complex functional relations by generalizing from a limited amount of known input/output training data. $\mathrm{NN}$ has its strength in learning and adaptation. The main learning algorithm that has been implemented is the back propagation (BP) in addition to the Subtractive Clustering approach. Neurofuzzy models are used to achieve the reasoning and learning capabilities. One of these Neurofuzzy approaches namely, Adaptive Network-based Fuzzy Inference Systems or Artificial NeuroFuzzy Inference Systems (ANFIS) [26] has been implemented. Using known pairs of input/output datasets, ANFIS constructs a fuzzy inference system (structural identification), or makes use of the generated clusters by the Subtractive Clustering model. The generated membership function parameters are then tuned using a learning rule such as the BP algorithm. This is the first time that the Neurofuzzy approach is implemented to address the modelling of the project management as illustrated in this paper.

\section{B. Description of the SKAM Model}

The proposed SKAM model, illustrated in Figure 2, is a two-stage Neurofuzzy-based system that uses the ten KAs' values as an input and models them individually. The outputs of all of these KAs are fed into the second stage. The processing of these ten inputs results in a value that describes and represents the status and competency of the management of the project under consideration. The following subsections will describe in more details the processing of these two stages.

Stage 1: Individually, each KA has been modelled based on the Neurofuzzy modelling technique to represent and describe the relations between all its 
associated processes with equal weights. These weights can be modified according to the organizational considerations, contexts and environment. The output of each of these models represents the relations between all of the involved input corresponding processes and the output, taking into account the contribution of all these inputs to produce the output. In other words, such a model depicts the quality of each KA as the linguistic terms: POOR, FAIR, GOOD and VERY GOOD. An example of these individual KAs is the Management of Integration, namely Integration, which is described in Figure 3. The Integration KA has six processes that influence its output.

The relations between these six input processes namely, Develop_Project_Charter; Develop_Project_ Management_Plan; Direct_and_Manage_Project_ Execution; $\quad$ Monitor_and_Control_Project_Work; Perform_Integrated_Change_Control; and Close_ Project_or_Phase, and the resulted outputs are described in this model to produce the output, namely, Integration_Management. With equal weights' contribution, the relationship between these processes and the produced output, Integration_Management, is described by the following rule:

Rule $\mathrm{R}_{\mathrm{i}}$ : if (Develop_Project_Charter is in $_{\mathrm{i}}$ cluster $\mathrm{r}_{\mathrm{i}}$ ) and (Develop_Project_Management_Plan is In2Cllusteri) and (Direct_and_Manage_Project_Execution is In3cluster $r_{i}$ ) and (Monitor_and_Control_Project_Workis in4cluster $r_{i}$ ) and (Perform_Integrated_Change_Control is in5cluster ${ }_{i}$ ) and (Close_Project_or_Phaseis in6cluster ${ }_{\mathrm{i}}$ )

Then Integration_Management is the $i^{\text {th }}$ linear $=p_{i}+$ $q_{i}+r_{i}[27]$
Where $i$ indicates the $i^{\text {th }}$ rule, that relates the $i^{\text {th }}$ inputs terms (Develop_Project_Charter, Develop_ Project_Management_Plan, Direct_and_Manage_ Project_Execution, Monitor_and_Control_Project Work, Perform_Integrated_Change_Control, and Close_Project_or_Phase) with the $i^{\text {th }}$ output (Integration_Management) $p_{i}, q_{i}$ and $r_{i}$ are parameters.

The tested and validated data to verify the performance of the SKAM model has been randomly generated. 250 pairs of datasets have been used to train and validate the SKAM model. For every individual model, 250 datasets have been split into training and checking datasets using the cross validation approach [27]. That is, $80 \%$ of the data has been used as the training set and the rest as the checking set (data that has not been shown to the model). Figure 5 illustrates the actual and predicted Integration_Management plots.

Similarly, all of the stated ten KAs have been modelled to produce the competency of each KA. Three measures have been used to check the adequacy of the developed models: the Mean Absolute Percentage Error (MAPE), which measures the average of the absolute percentage errors of forecasts as in equation (1); the Correlation Coefficient (CC) measure, which determines the degree to which two variables' movements are associated as in equation (2); and the Max Percent Error (MPE) between the calculated and predicted values as in equation (3). These measures are calculated using the following formulae:

$$
\text { MAPE }=\frac{1}{n} \sum_{i=1}^{n}\left|\frac{\text { Calculated }_{i}-\text { Predicted }_{i}}{\text { Calculated }_{i}}\right|
$$

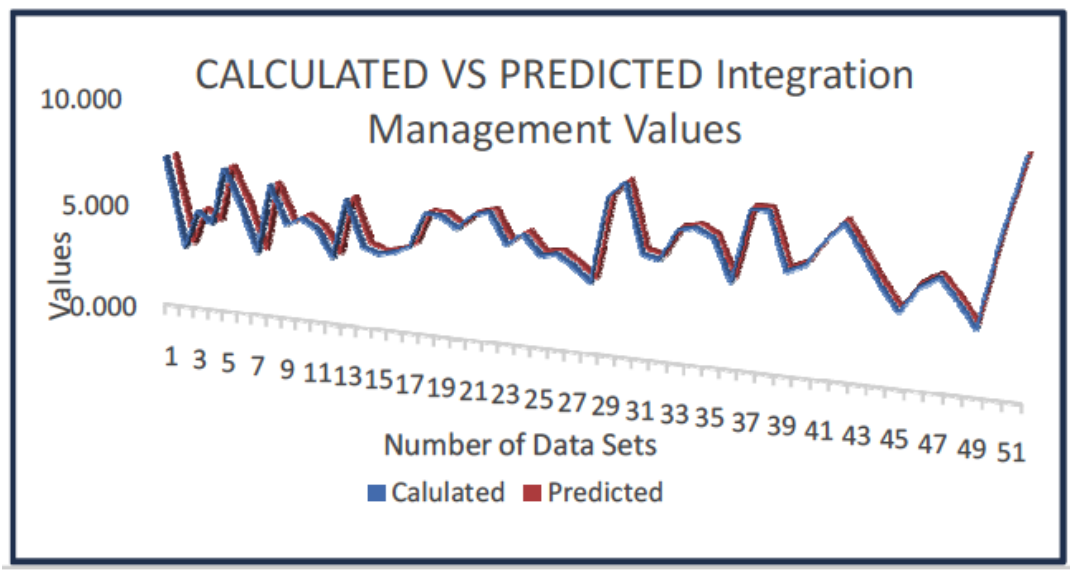

Figure 5: Calculated Vs. Predicted Integration_Management plots. 
Where $\mathrm{n}$ is the number of values.

$C C_{\text {Predicted } \text { Calculated }}=$

${\sqrt{\left[1-\sum_{i}\left(\text { Calculated }_{i}-\text { Predicted }_{i}\right)\right)^{2} / \sum_{i}\left(\text { Calculated }_{i}-\text { Calculated }^{2}\right]^{2}}}^{(2)}$

$M P E=M A X\left(\frac{\mid \text { Calculted }- \text { Pr edicated } \mid}{\text { Calculted }} \times 100\right)$

Stage 2: The outputs of these ten models are inputs, with equal weights, to the overall Neurofuzzy model as shown in Figure 4. The weights of these inputs can be modified according to the organizational concerns. This overall model describes the relationships of the produced outputs of the ten KAs, in the first stage (input), and the produced overall output competency of the system. It is worth mentioning that all inputs have contributed equally to produce the output of the system.

Figure 6 Illustrates the internal structure of the overall SKAM model. The rules that govern the model have the following form:

Rule $R_{i}$ : if (Integration is in1cluster $r_{i}$ ) and (Scope is In2Cllusteri) and (Time is In3cluster ${ }_{i}$ ) and (Cost is in4cluster $r_{i}$ ) and (Quality is in5cluster ${ }_{i}$ ) and ( $H R$ is in6cluster ${ }_{i}$ ) and (Communications is in7cluster ${ }_{i}$ ) and (Risk is in8cluster ${ }_{i}$ ) and (Procurement is in9cluster ${ }_{i}$ ) and (Stakeholders is in10 cluster $_{i}$ ) then Overall_Knowledge_Areas is the $i^{\text {th }}$ linear $=p_{i}$ $+q_{i}+r_{i}[27]$

Where $i$ indicates the $i^{\text {th }}$ rule that relates the $i^{\text {th }}$ inputs terms (Integration, Scope, Time, Cost, Quality, HR, Communications, Risk, Procurement, Stakeholders) with the $i^{\text {th }}$ output (Overall_Knowledge_Areas) $p_{i}, q_{i}$ and $r_{i}$ are parameters.

\section{SKAM Simulated Version}

A simulated version of the SKAM version has been developed as shown in Figure 7, in order to obtain the overall project management competency. The SKAM simulated tool provides a friendly user interface, where any value in the range between 0.0 and 10.0 is used as an input to any $\mathrm{KA}(\mathrm{s})$ as in the first stage. Furthermore, the interface provides the user the ability to set any value for the KAs and accordingly predict the overall performance, competency and capability of the project under consideration. Figure 8 illustrates this SKAM capability. As shown in Figure 8, KAs have been randomly set as: 6.3 to Integration, 7.04 to Scope, 4.61 to Time, 3.93 to Cost, 4.11 to Quality, 3.48 to HR, 7.26 to Communications, 6.52 to Risk, 8.94 to Procurement, and 6.51 to Stakeholders.

The predicted output is equal to 5.57. Following a scale of a four-level Likert one: $0-<2.5$ is POOR; 2.5 $<5$ IS FAIR; $5-<7.5$ IS GOOD and $7.5-10$ is VERY

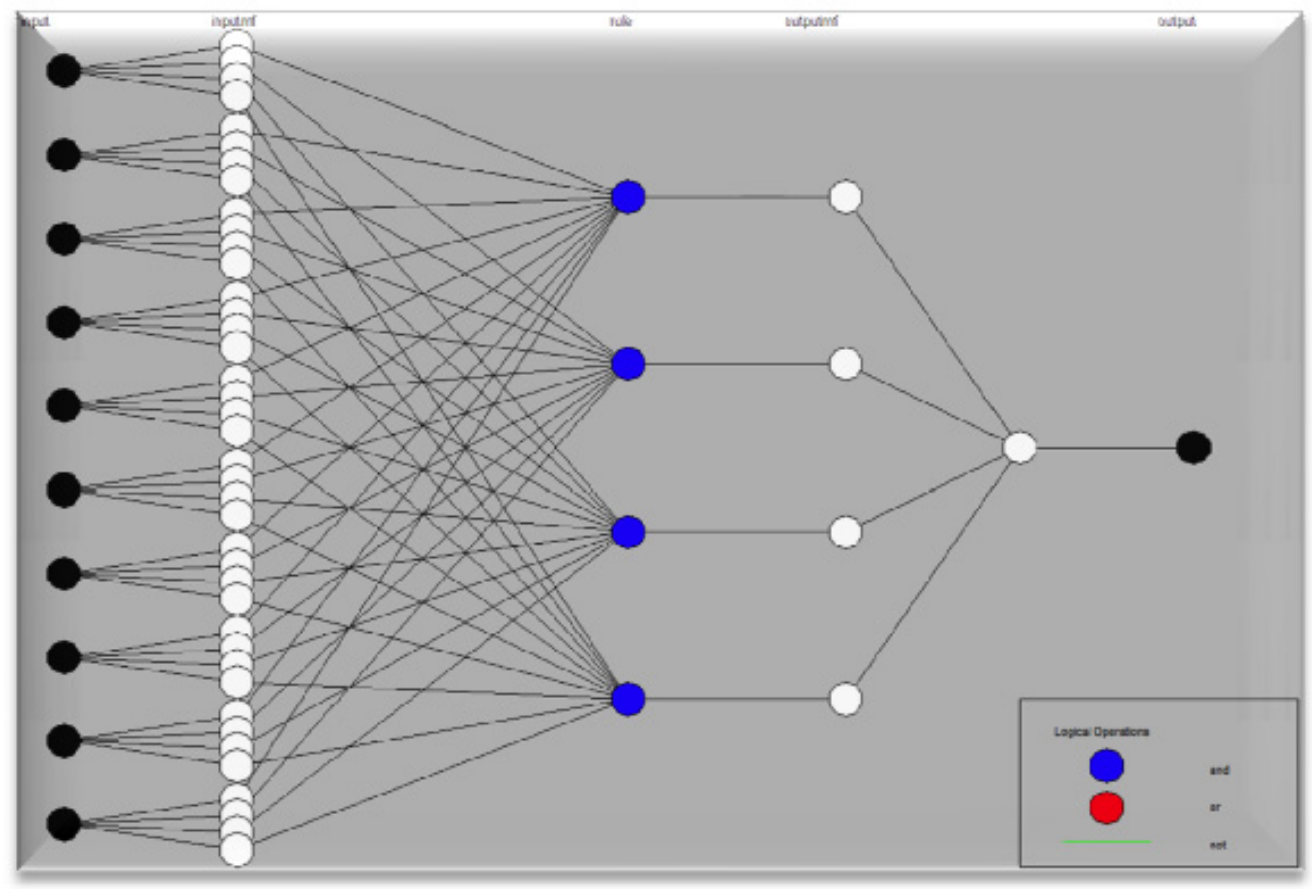

Figure 6: The internal structure of the SKAM Model. 


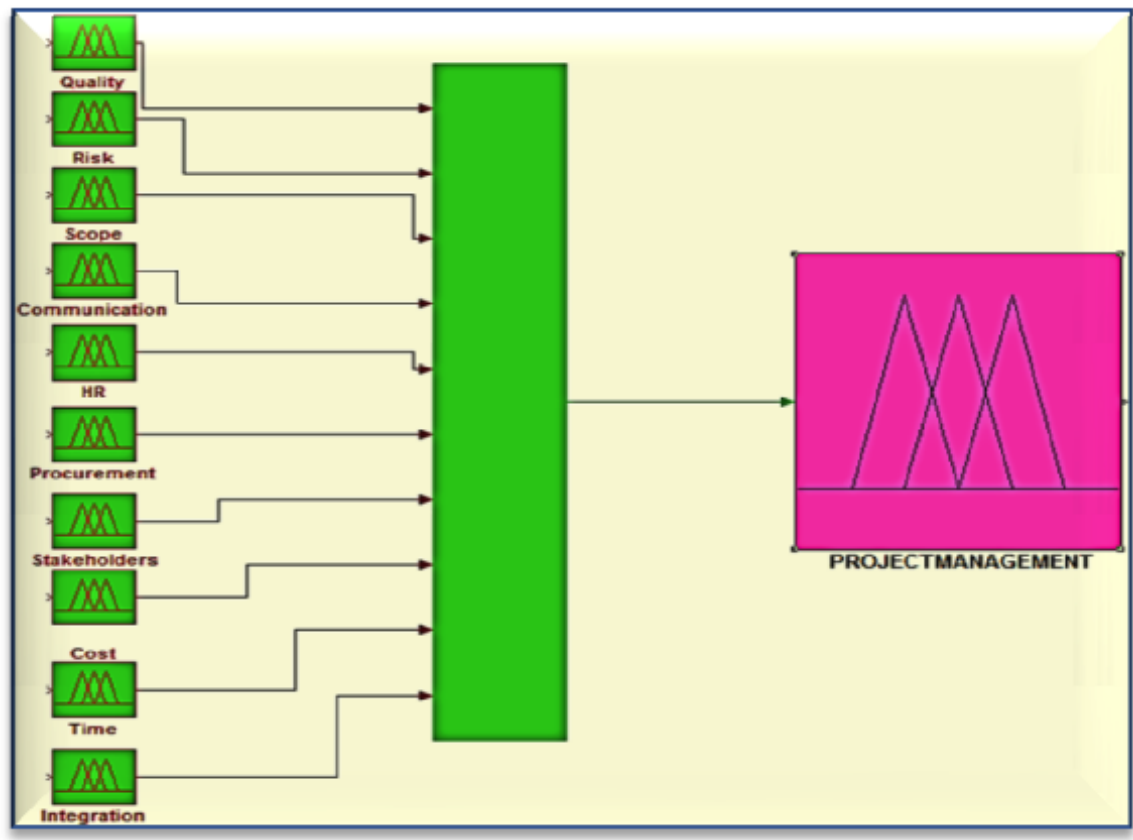

Figure 7: The SKAM Simulated Version.



Figure 8: The SKAM Simulated Input-Output.

GOOD. The overall competency of the project under consideration is GOOD.

\section{RESULTS AND DISCUSSION}

The SKAM model has been developed to assess the competency of the various KAs including the overall KA. A sample of SKAM first stage is as depicted in Figure 3. To validate the models, datasets have been randomly generated in the range 0.0 to 10.0 . That is, a 0.0 to 10.0 scale has been used to assess each KA.

It is assumed that such a scale represents four categories: POOR to cover the range between 0.0 to less than 2.5; FAIR to cover the range from 2.5 to less than 5.0; GOOD to represent 5.0 to less than 7.5 range; and VERY GOOD to represent the 7.5 to 10 range.

For each KA model, the associated processes are given values between 0.0 and 10 . The calculated output, the competency of that particular KA, is the average of these input values. This assessment is mainly based on the evaluation or judgment of all related processes. The assessment outputs of all KAs are combined together to provide the overall KAs' competency. 250 datasets have been randomly generated and split into training and checking datasets using the cross validation approach [27].In other words, $80 \%$ of the data has been used as the training set, and 
the remaining 50 data sets have been used as the checking set that contains the non-seen data to the model.

The Softcomputing approach has been used to develop such models. Authors of this paper have tried several Softcomputing techniques. These include Neurofuzzy with a hybrid Learning Algorithm, Subtractive Clustering, and a combination of the Subtractive Clustering and the Neurofuzzy approaches. The best results have been obtained by making use of the Subtractive Clustering and the Neurofuzzy approaches. Thus, all of the developed models are based on the combinations of the two approaches.

Figure 5 shows the calculated and predicted competency values of the Integration management model. The obtained three measures for all models in the two phases are shown in the three figures.

Figure 9 illustrates the various obtained MAPE values for all 11 models (ten KAs and the overall KA). MAPE ranges between 0.3618 for the HR management model to 0.5751 for the Communications Management model. The achieved MAPE value for the overall model is 0.415 . MAPE values measure the accuracy of the predicted output. These small MAPE values reflect the high accuracy of the various developed models. Such accuracy has been consistent with the obtained values of the CC measure. The obtained $\mathrm{CC}$ values are shown in Figure 10. The obtained high $\mathrm{CC}$ values that range between 0.9996 and 0.9999 show the adequacy of such models to predict the competencies of the various KAs. The CC measure determines the degree to which two variables' movements, calculated and predicted values, are associated. Moreover, the attained MPE measure values, shown in Figure 11, are in consistence with the other used measures. The various obtained MPE values range between 0.76 and 4.73 The percentage error (PE) provides the difference between the calculated and the predicted values as a percentage of the calculated value that help see how close the prediction is to the calculated value. MPE provides the maximum of these closeness. Finally, Figure 12 compares the calculated and predicted values of the overall KAs or competency.

These results reflect the adequacy of applying the Softcomputing approach to the field of project management, particularly, the prediction or assessment of a project's competency.

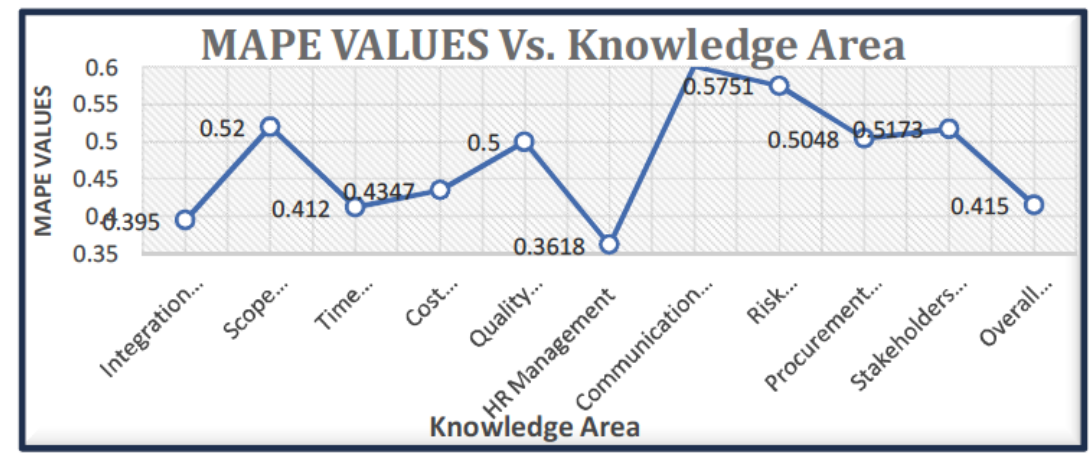

Figure 9: MAPE Values Vs. Knowledge Area Plot.

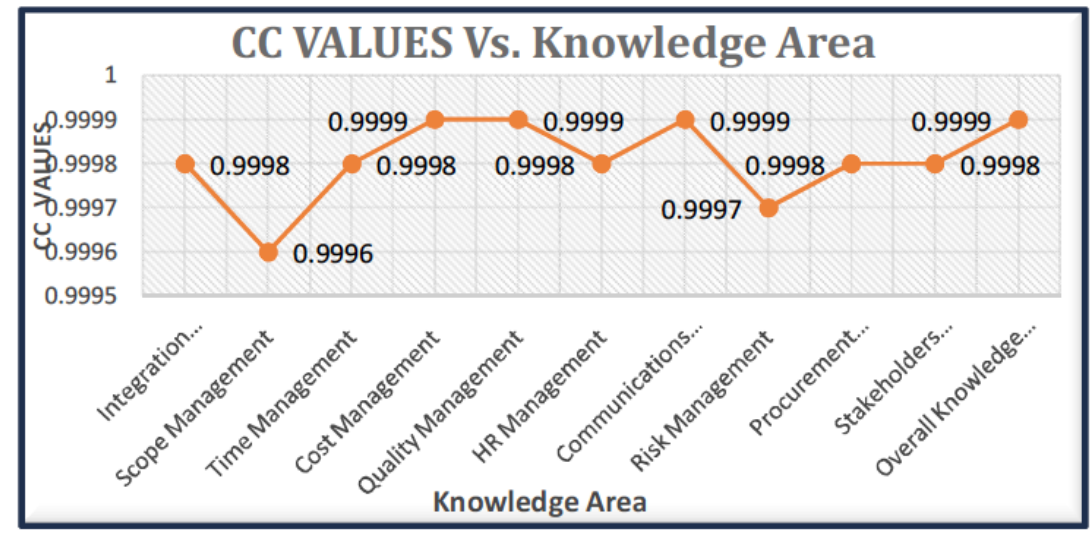

Figure 10: Correlation Coefficient Values Vs. Knowledge Area Plot. 


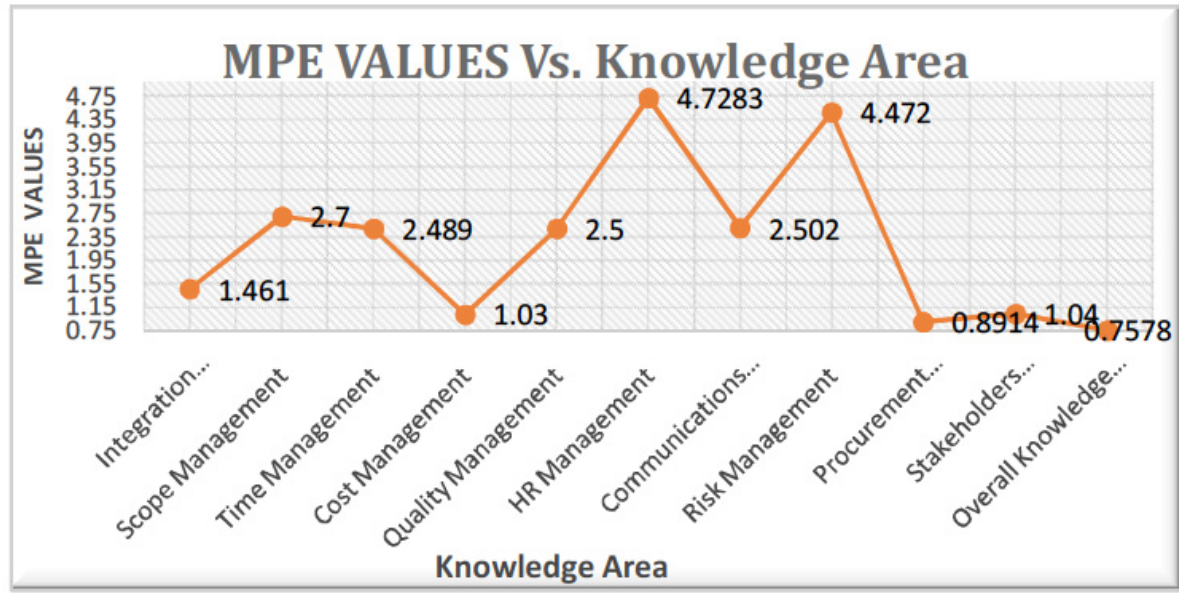

Figure 11: Maximum Percentage Error Values Vs. Knowledge Area Plot.



Figure 12: Overall Calculated Vs. Predicted Knowledge Areas Plot.

\section{CONCLUSION AND FUTURE WORK}

A Softcomputing-based SKAM model has been developed to predict each KA depending on their individual associated processes that are treated as black boxes. An overall competency assessment has also been achieved in the second stage of the SKAM model. The ten KAs are as provided by the $5^{\text {th }}$ edition of the PMBOK® Guide. The validation of these models has been accomplished by randomly generating 250 datasets. Using the cross validation algorithm, the generated datasets have been split into training and checking datasets. Three measures have been used to validate the adequacy and accuracy of such models: MAPE, CC and MPE. The highest obtained MAPE, CC and MPE values are 0.5751, 0.9999, and 4.7283, respectively. These consistent values reflect the potential, adequacy and suitability of the Softcomputing approach to assess the competency of KAs in the field of project management.

A future research study should focus on validating such models against benchmarks real data before stating the adequacy of applying the Softcomputing approach to the field of project management. Furthermore, the details of each process should also be addressed. Such details include inputs, tools and techniques, and outputs as well as tailoring it to one of the five groups of processes.

\section{REFERENCES}

[1] A Guide to the Project Management Body of Knowledge (PMBOK® Guide) - Fifth Edition, http://www.pmi.org/ PMBOK-Guide-and-Standards.aspxAccessed on 15.04.2015

[2] https://www.apm.org.uk/APM5Dimensions Accessed on 15.04.2015 
[3] http://www.pmsolutions.com/resources/view/what-is-theproject-management-maturity-model/ Accessed on 18.04.2015

[4] https://www.prince2.com/what-is-prince2 Accessed on 18.04.2015

[5] http://www.pmi.org/PMBOK-Guide-and-Standards.aspx Accessed on 20.04.2015

[6] Singh R, Lano K. Literature Survey of previous research work in Models and Methodologies in Project Management. (IJACSA) International Journal of Advanced Computer Science and Applications 2014; 5(9). http://dx.doi.org/10.14569/IJACSA.2014.050917

[7] Ramadan WH. Project Management Literature: Gaps and Opportunities. E-Leader Berlin 2012.

[8] Siwani M, et al. Application of fuzzy logic for improved software project management estimations Electrical and Computer Engineering, 2004. Canadian Conference on 2004; Volume 4: pp. 1897-1900.

http://dx.doi.org/10.1109/CCECE.2004.1347582

[9] Goonawardene N, et al. A Neural Network Based Model for Project Risk and Talent Management. Advances in Neural Networks - ISNN 2010, Lecture Notes in Computer Science 2010; 6064: 532-539.

[10] Hu Y, Huang J, Chen J, Liu M, Xie K. Software project risk management modeling with neural network and support vector machine approaches. In: ICNC 2007: Proceedings of the Third International Conference on Natural Computation, pp. 358-362. IEEE Computer Society, Washington 2007. http://dx.doi.org/10.1109/icnc.2007.672

[11] Liu XF, Kane G, Bambroo M. An intelligent early warning system for software quality improvement and project management. Journal of Systems and Software 2006; 79(11): 1552-1564.

[12] Tüysüz F, Kahraman C. Project Risk Evaluation Using a Fuzzy Analytic Hierarchy Process: An Application Information Technology Projects. International Journal of Intelligent Systems 2006; 21: 559-584.

\section{http://dx.doi.org/10.1002/int.20148}

[13] Recent Advances in Technologies, Edited by Maurizio A Strangio, ISBN 978-953-307-017-9, Published online 01, November, 2009, InTech, Hossein Iranmanesh, et al, "Framework of Intelligent Systems to Support Project Scope".

[14] Avots, Ivars. Application of expert systems concepts to schedule control. Project Management Institute 2001.
[15] Nemati H, Todd DW, Brown, Paul D. A hybrid intelligent system to facilitate information system project management activities. Project Management Institute 2002.

[16] Nassa VK, Yadav SK. Project Management Efficiency -A Fuzzy Logic Approach. International Journal of Engineering and Advanced Technology (IJEAT) ISSN: 2249-8958, Volume-1, Issue-3, February 2012

[17] Nassa VK, Yadav SK. Project Management Efficiency using Soft Computing and Risk Analysis. International Journal of Computer Applications 2012; 50(16): 17-22.

[18] Hwang B-G, Ng WJ. Project management knowledge and skills for green construction: Overcoming challenges. International Journal of Project Management 2013; 31(2): 272-284.

[19] Eastham J, et al. PLM software selection model for project management using hierarchical decision modeling with criteria from PMBOK knowledge areas. Technology Management in the IT-Driven Services (PICMET), 2013 Proceedings of PICMET '13: July 28 2013-Aug. 1 2013, 511 $-527$.

[20] Bai-Min S, et al. Notice of Retraction Primarily Research on Knowledge Audit for Evaluating Enterprise Knowledge Management Capability, Published in: Management and Service Science, 2009. MASS '09, International Conference on: 20-22 Sept. 2009; 1-5. http://dx.doi.org/10.1109/ICMSS.2009.5302226

[21] Spalek S. Assessing project management maturity in the area of knowledge management in select companies International Journal of Economics, Finance and Management Sciences 2014; 2(2): 164-170. http://dx.doi.org/10.11648/j.ijefm.20140202.18

[22] http://www.corpedgroup.com/consulting/online-skillsassessment.asp

[23] Zadeh LA. Fuzzy Logic, Neural Networks and Soft computing. Communications of ACM 1994; 37(3): 77-84.

[24] Zadeh L. 'Fuzzy sets'. Information and Control 1965; 8: 338353.

http://dx.doi.org/10.1016/S0019-9958(65)90241-X

[25] http://www.cs.berkeley.edu/ zadeh/ Accessed on 22.04.2015

[26] Jang J-SR. ANFIS: adaptive-network-based fuzzy inference systems. IEEE Transactions on Systems, Man, and Cybernetics, 1993; 23(3): 665-685.

[27] Jang J-SR, Sun C-T. Neuro fuzzy modeling and control. IEEE Proc 1995; 83(3): 378-405.

(c) 2015 Arafeh and Mufid; Licensee Lifescience Global.

This is an open access article licensed under the terms of the Creative Commons Attribution Non-Commercial License (http://creativecommons.org/licenses/by-nc/3.0/) which permits unrestricted, non-commercial use, distribution and reproduction in any medium, provided the work is properly cited. 